\title{
Nível de conhecimento discente acerca da contabilidade ambiental
}

A Contabilidade Ambiental tem um importante papel na sociedade e para as empresas. Ela é uma ferramenta importante para o desenvolvimento sustentável, além de ser essencial para as empresas obterem vantagens no mercado. Dado a importância da Contabilidade Ambiental, essa pesquisa teve por objetivo verificar o nível de conhecimento dos discentes de Ciências Contábeis da Universidade Federal de Pernambuco em relação a esse tema, além de observar a importância dada pelos alunos acerca do tema. Para tanto, utiliza-se o método survey, fazendo uso de um questionário divido em três blocos, procurando traçar o perfil do aluno, medir a importância dada por ele acerca da Contabilidade Ambiental e seu nível de conhecimento sobre esse tema. $\mathrm{O}$ questionário foi aplicado online aos estudantes de Ciências Contábeis matriculados no semestre de 2019.2. Os resultados indicaram que, a maioria dos discentes tem interesse em cursar a disciplina de Contabilidade Ambiental caso essa seja ofertada, além de atribuírem grande importância a temas a ela relacionados. Porém, os discentes apresentaram baixo nível de conhecimento quanto aos temas relacionados a Contabilidade Ambiental, o que pode ser um reflexo da pouca importância dada pelos professores acerca da Contabilidade Ambiental, segundo os discentes.

Palavras-chave: Contabilidade Ambiental; Educação Contábil; Survey; Nível de Conhecimento.

\section{Level of student knowledge about environmental accounting}

Environmental accounting has an important role in society and for companies. It is an important tool for sustainable development, in addition to being essentia for companies to obtain advantages in the market. Given the importance of Environmental Accounting, this research aimed to verify the level of knowledge of students of Accounting Sciences at the Federal University of Pernambuco in relation to this topic, in addition to observing the importance given by students on the topic. For this, the survey method is used, making use of a questionnaire divided into three blocks, trying to trace the student's profile, measure the importance given by him about Environmental Accounting and his level of knowledge on this topic. The questionnaire was applied online to accounting students enrolled in the semester of 2019.2. The results indicated that most students are interested in taking the Environmental Accounting discipline if it is offered, in addition to attaching great importance to topics related to it. However, the students presented a low level of knowledge regarding the themes related to Environmental Accounting, which may be a reflection of the little importance given by teachers about Environmental Accounting, according to the students.

Keywords: Environmental Accounting; Accounting Education; Survey; Knowledge level.

Topic: Contabilidade Geral

Reviewed anonymously in the process of blind peer.
Received: $16 / 11 / 2019$

Approved: 22/03/2020
Igor Coutinho da Silva

Universidade Federal de Pernambuco, Brasil

http://lattes.cnpq.br/8365371817213489

igor.coutinhoufpe@gmail.com

\section{José Jonas Alves Correia (iD}

Universidade Federal de Pernambuco, Brasil

http://lattes.cnpq.br/2582627606928274

http://orcid.org/0000-0003-4552-7263

profjonasalves@gmail.com

Antoniel dos Santos Gomes Filho (iD

Centro Universitário Vale do Salgado, Brasil

http://lattes.cnpq.br/9563145614494252

http://orcid.org/0000-0003-2230-4315

antoniel.historiacomparada@gmail.com

\section{Referencing this:}

SILVA, I. C.; CORREIRA, J. J. A.; GOMES FILHO, A. S.. Nível de conhecimento discente acerca da contabilidade ambiental. Business Journal, v.2, n.1, p.28-38, 2020. DOI:

http://doi.org/10.6008/CBPC2674-6433.2019.001.0003 


\section{INTRODUÇÃO}

Para atender seus objetivos socioeconômicos, o ser humano acaba afetando o meio-ambiente. Com os objetivos de lucrar e se desenvolver sendo alcançados, pode-se haver um desequilíbrio no ambiente, dependendo do impacto gerado por estes objetivos citados e suas ações para alcançá-los. A poluição ambiental tem sido o foco de muitas discussões em empresas, governos e sociedade, tendo a atenção de parte dos acadêmicos de diversas áreas, já que países e a sociedade em si têm buscado formas de amenizar os impactos sobre o meio-ambiente (CARVALHO et al., 2010).

Uma das áreas acadêmicas com interesse nos impactos ambientais é a Contabilidade, se preocupando com desenvolvimento sustentável e a contabilização apropriada dos recursos naturais utilizados na produção de seus ativos e suas consequências sobre o ambiente. A crescente demanda por sustentabilidade, faz empresas darem maior atenção a legislações ambientais e outras disposições legais que se referem ao meio ambiente (REBOLLO, 2001).

Segundo Ferreira (2003), a Contabilidade ambiental surgiu com o objetivo de auferir os resultados de uma empresa referentes a suas atividades relacionadas ao meio ambiente. Além disso, ela contribui para uma melhor responsabilidade social, algo que as empresas passaram a assumir há alguns anos. Essa questão não é algo momentâneo, com isso, as empresas passaram a divulgar suas ações positivas referentes ao desenvolvimento sustentável, além de uma transparência sobre o real impacto das ações das empresas sobre o meio ambiente (LEONARDO, 2003).

Por mais que a área ambiental venha ganhando força nos últimos anos, pode-se notar que não é algo discutido entre os discentes de contabilidade, seja por falta de abordagem ou interesse. Com essa área crescendo cada vez mais e requisitando profissionais com conhecimento desse ramo, surge uma questão problemática: qual o nível de conhecimento dos discentes de ciências contábeis acerca da área de Contabilidade Ambiental?. Nesta ótica, o estudo tem como objetivo avaliar o nível de conhecimento dos discentes de ciências contábeis sobre a área da contabilidade Ambiental, verificando se estes estão familiarizados com a temática.

Esse estudo se justifica pela necessidade de alunos de ciências contábeis terem pelo menos o mínimo de conhecimento sobre a área ambiental, além de observar se há interesse sobre a área, dado que a sustentabilidade é uma questão muito debatida atualmente. A pesquisa contribui para o Projeto Político Pedagógico (PPP) sobre adicionar conteúdo referentes a Contabilidade Ambiental, já que a Contabilidade pode e deve ser uma ferramenta que auxilia as entidades a serem mais sustentáveis, além de causar um impacto positivo na sociedade. A relevância dessa pesquisa também se baseia na necessidade de melhorar a qualidade da educação contábil, podendo essas informações serem úteis a órgãos de classe, discentes, docentes e coordenadores do curso, para que possam refletir sobre a importância e necessidade do tema Contabilidade Ambiental.

Essa pesquisa é dividia em cinco tópicos da seguinte forma: o primeiro é a introdução onde será exposto o problema e a justificativa da pesquisa. No segundo, referencial teórico onde serão apresentados 
conceitos e estudos anteriores para embasar essa pesquisa, seguido da metodologia, onde será exposto o método da coleta de dados e a análise. A quarta parte consiste nos resultados da pesquisa e a discussão acerca dela. Por último, terão as considerações finais.

\section{REVISÃO TEÓRICA}

\section{Contabilidade Ambiental}

A Contabilidade Ambiental é o estudo do patrimônio ambiental das entidades, tendo o objetivo de fornecer aos seus usuários, sejam internos ou externos, sobre eventos ambientais que venham causar modificações nesse patrimônio, bem como identificar, mensurar e evidenciar (SANTOS et al., 2001). Os eventos vão desde investimentos realizados para a proteção de eventuais danos ecológicos até despesas para correção dos efeitos causados pela empresa.

Segundo Guimarães (2000), o meio ambiente é um conjunto de elementos vivos ou não que constituem o planeta Terra, se influenciando por meio de relações entre si de forma equilibrada. Durante o século $\mathrm{XX}$, questões da temática ambiental começaram a ganhar força pelo mundo todo, alguns anos após as revoluções industriais. Com a ideia de desenvolvimento sustentável apareceu e logo foi relacionada ao desenvolvimento econômico. A indústria evoluiu, mas com ela, os problemas ambientais aumentaram, gerando a degradação da qualidade ambiental (SEIFFERT, 2009).

Segundo Gonçalves et al. (2005), a Contabilidade integra parte de uma das ciências mais antigas do mundo, modificando-se e adaptando-se conforme a sociedade ia mudando. Ela não pode e nem deve ignorar os problemas ambientais, dado que a mesma é o elo entre a comunidade e empresas. Do início a meados da década de 70, a Contabilidade Ambiental começou a ser abordada, e foi definida como a contabilização dos benefícios e prejuízos que um produto ou serviço pode causar ao meio ambiente ao ser desenvolvido, também tendo um conjunto de ações planejadas afim de desenvolver um projeto, se preocupando com esse mesmo meio ambiente (CONCEIÇÃO et al., 2014).

A Contabilidade Ambiental passou de fato a fazer parte das empresas em 1974, quando houve uma crise do petróleo, tendo seus preços elevados e o produto em si escasso. Naquela época, um grupo de cientistas do mundo todo de juntaram preocupados em discutir o futuro do mundo, em relação ao meio ambiente. Este grupo ficou conhecido como 'Grupo de Roma', que divulgou um relatório chamado 'limites de crescimento', onde mostrava que as pessoas e principalmente as empresas deveriam se preocupar com os efeitos que suas ações geravam sobre o meio ambiente, pois caso o contrário, haveria uma escassez de recursos naturais mais rápido do que se esperava, além de impactos negativos sobre a saúde das pessoas e a economia. Com isso, mudou-se a ideia de que a preocupação para se preservar o meio ambiente era só de grupos governamentais e ambientalistas, passando a ser da humanidade como um todo, já que a sobrevivência de todos depende disso (GONÇALVES et al., 2005).

Gonçalves et al. (2005) dizem que a contabilidade ambiental se torna um importante instrumento de gestão, pois esta facilita a integração das questões ambientais à estratégia da empresa e sua cadeira 
operacional. Ela promove transparência quando as atitudes da empresa em relação ao meio ambiente, mostrando o desempenho da empresa nesse âmbito além de evidenciar a responsabilidade social da entidade. Diante desse contexto, será exposto no Quadro 1 alguns conceitos ligados a Contabilidade Ambiental.

Quadro 1: Conceitos referentes itens da Contabilidade Ambiental.

\begin{tabular}{|c|c|}
\hline Item & onceito \\
\hline $\begin{array}{l}\text { Ativo } \\
\text { ambiental }\end{array}$ & $\begin{array}{l}\text { Um ativo ambiental é definido como todos os bens e direitos que tem como objetivo controle, recuperação e } \\
\text { preservação do meio ambiente, sendo eles de capital circulante ou fixos. Exemplos: estoque de insumos que } \\
\text { são utilizados nos processos de eliminação ou redução de poluição e investimentos adquiridos ou produzidos } \\
\text { que visão diminuir o impacto causado ao meio ambiente. }\end{array}$ \\
\hline $\begin{array}{l}\text { Passivo } \\
\text { ambiental }\end{array}$ & $\begin{array}{l}\text { Um passivo ambiental são benefícios econômicos que serão sacrificados para lidar com as obrigações } \\
\text { adquiridas, tenham sido voluntariamente ou involuntariamente, destinadas a preservação ou recuperação do } \\
\text { meio ambiente perante a terceiros. A origem dos gastos ambientais se dá em toda agressão praticada ou que } \\
\text { ainda se pratica ao meio ambiente. Ele representa toda obrigação de curto ou longo prazo destinados a } \\
\text { promover unicamente investimentos em função da diminuição ou extinção de danos ao meio ambiente, } \\
\text { podendo incluir ainda percentual do lucro do exercício, com destinação compulsória a investimentos na área } \\
\text { ambiental. }\end{array}$ \\
\hline $\begin{array}{l}\text { Receita } \\
\text { ambiental }\end{array}$ & $\begin{array}{l}\text { A receita ambiental se define como o acréscimo de benefícios seja na entrada de ativos ou na diminuição da } \\
\text { exigibilidade ambiental, se revertendo em acréscimo no patrimônio líquido. Exemplo: prestação de serviços } \\
\text { focado em gestão ambiental e venda de produtos que foram feitos com a sobra dos insumos. }\end{array}$ \\
\hline $\begin{array}{l}\text { Balanço } \\
\text { ambiental }\end{array}$ & $\begin{array}{l}\text { É uma demonstração que evidencia o ativo e passivo ambiental, tal como os fenômenos ambientais que } \\
\text { ocorreram naquele período em questão. Ele permite quantificar itens relacionados aos impactos ambientais, } \\
\text { além de ser possível propor melhorias e identificar oportunidades de valorização dos ativos ambientais através } \\
\text { dele. }\end{array}$ \\
\hline $\begin{array}{l}\text { Custo } \\
\text { despesas } \\
\text { ambientais }\end{array}$ & $\begin{array}{l}\text { Os custos e despesas ambientais são os gastos diretos ou indiretos no processo produtivo e em atividades } \\
\text { ecológicas da entidade. Se forem aplicados diretamente na produção, são contabilizados como custo, e se } \\
\text { forem indiretos, como despesa. Os custos também podem ser divididos em internos e externos. Os internos } \\
\text { são os contabilizados ao longo do processo de produção, servindo de base para determinar o preço dos } \\
\text { produtos, tendo como exemplo a matéria prima. Já externos, são os gerados pelo impacto ambiental e social } \\
\text { da empresa devido as suas atividades, os quais a entidade não se responsabiliza financeiramente, como por } \\
\text { exemplo, a poluição do ar. }\end{array}$ \\
\hline
\end{tabular}

Fonte: Adaptado de Santos et al. (2001) e Conceição et al. (2014).

\section{Estudos anteriores}

Nesta seção serão apresentados estudos realizados anteriormente que buscaram analisar o nível de conhecimento ou interesse de contadores, discentes e docentes de ciências contábeis referente a assuntos da área contábil. Tais achados dão aso para discussão do objeto desta investigação. Maciel et al. (2009) analisaram o nível de conhecimento dos profissionais de Contabilidade sobre as peculiaridades da Contabilidade Ambiental. Os achados apontaram que, 37\% afirmaram desconhecer totalmente a temática, 15\% conhecem razoavelmente e ninguém disse conhecer totalmente. De maneira expressiva, 40\% nunca ouviram falar das peculiaridades da Contabilidade Ambiental e 100\% afirmaram nunca ter exercido qualquer atividade relacionada a está área em específico.

Carvalho et al. (2010) analisaram o interesse dos estudantes de Ciências Contábeis pela área da Contabilidade Ambiental. Os resultados das assertivas mostram que cerca de $70 \%$ veem a disciplina de Contabilidade Ambiental ou correlata relevantes no componente curricular, $17 \%$ discordam e $13 \%$ se mantiveram neutros. Os números de interesse se aproximam resultados obtidos na pergunta anterior, tendo 71\% considerando disciplinas da Contabilidade Ambiental interessantes para sua formação, $11 \%$ discordando e $18 \%$ se mantiveram neutros. No total, os discentes concordaram com $81 \%$ das assertivas, discordaram de $14 \%$ e de mantiveram neutros em $5 \%$, mostrando que a maioria acha importante disciplinas de Contabilidade 
Ambiental.

Lima Filho et al. (2013), verificam a compreensão dos estudantes dos Cursos Ciências Contábeis em Salvador a respeito do conceito de passivo ambiental. Também buscaram entender como o ensino da disciplina Teoria da Contabilidade contribui na discussão desse conceito. Esse é um dos vários exemplos que existem quanto a medição do nível de conhecimentos de discentes, docentes e contadores acerca de assuntos da Contabilidade.

Ribeiro (2018) analisou o nível de conhecimento dos estudantes e profissionais de Contabilidade da cidade de Santana do Ipanema localizada no sertão alagoano, sobre a Contabilidade ambiental. 0 estudo mostra que $71 \%$ nunca cursaram a disciplina Contabilidade Ambiental ou correlata. Dos professores, 50\% afirmam ter conhecimento insuficiente e $25 \%$ nenhum conhecimento sobre ativos e passivos ambientais. Entre os contadores, 43\% não afirmam não ter nenhum conhecimento de ativos e passivos ambientais.

Melo (2018) identificaram a percepção ambiental dos alunos, professores e coordenadores, assim como as dificuldades que encontravam para discutir questões referentes ao meio ambiente. Os alunos dos cursos de graduação que participaram do estudo, possuem uma compreensão desacertada a respeito da educação ambiental. Os professores por sua vez, alegaram que não discutem a temática ambiental em sala de aula porque o tema não faz parte dos ementários dos componentes curriculares, alegando desinteresse dos alunos e da instituição. O desinteresse dos alunos é questionável uma vez que mais de $50 \%$ deles afirmaram o contrário, algo que é perceptível quando observado a quantidade de matriculados nas poucas disciplinas com conteúdo ambiental oferecidas pelos cursos.

Galvão et al. (2019) identifica o nível de compreensão das notas explicativas pelos discentes do curso de Ciências Contábeis da Universidade Federal do Ceará (UFC). Apenas 1/3 dos alunos se consideram pleno conhecedor sobre as notas explicativas, representando $32 \%$ dos entrevistados. Já para os neutros representam $38 \%$ sobre o assunto e $30 \%$ afirmam não possuir conhecimentos específicos sobre o tema.

\section{METODOLOGIA}

\section{Tipologia da Pesquisa}

A pesquisa é descritiva e exploratória, dado que foi realizado uma pesquisa para que um estudo fosse feito sobre o objeto investigado, além de buscar descobrir o nível de interesse e o perfil da amostra que respondeu a pesquisa. Segundo Churchill Junior (1987), a pesquisa descritiva busca interpretar a realidade sem nela interferir, expondo as características de determinada população ou fenômeno. Para Malhotra (2001), o objetivo principal da pesquisa exploratória é possibilitar a compreensão do problema e enfrentado pelo pesquisador, visando proporcionar uma maior familiaridade com a situação para prover critérios e compreensão. O objeto da pesquisa são os discentes do curso Ciências Contábeis da Universidade Federal de Pernambuco, a fim de mensurar o conhecimento e interesse sobre Contabilidade Ambiental.

A abordagem escolhida foi a quantitativa, buscando obter resultados estatísticos e fazendo uma análise deles (BEUREN, 2004). Ela se baseia em uma medida de poucas variáveis objetivas, dando ênfase na 
comparação de resultados (WAINER, 2007).

O estudo também se caracteriza como um survey, visando apresentar a opinião das pessoas por meio de questionários e/ou entrevistas (GIL, 2014). O questionário foi feito de forma semiestruturada, usando a Escala Likert, tendo opções variando de 1 a 5, cuja primeira opção correspondia a discordância total e a última, concordando totalmente. As perguntas foram feitas para identificar a dimensão da consciência e conhecimento dos discentes regularmente matriculados em 2019.2 quanto a Contabilidade Ambiental.

O instrumento contém três blocos: o primeiro visando perfilar os respondentes da pesquisa, apontando gênero, idade, semestre em curso, dentre outros pontos; a segunda parte do instrumento é composto por assertivas em que o respondente atribui importância à Contabilidade Ambiental; o terceiro bloco e último traz afirmativas sobre a Contabilidade Ambiental, nesta parte, busca-se mensurar o nível de conhecimento do discente sobre o tema em estudo.

O questionário foi aplicado de forma online entre os meses de novembro e dezembro e teve como público-alvo os discentes de Ciências Contábeis da Universidade Federal de Pernambuco. Para analisar os dados utilizou-se a análise de conteúdo dos dados coletados e tratados por meio da ferramenta do Microsoft Excel, cujos resultados são expostos na próxima seção.

\section{RESULTADOS E DISCUSSÃO}

\section{Perfil dos respondentes}

Para medir o nível de conhecimento dos discentes de Ciências Contábeis da Universidade Federal de Pernambuco acerca da Contabilidade Ambiental, foi realizada uma coleta por meio de um questionário divido em 3 blocos, resultando em 106 respostas do total de 850 alunos matriculados no semestre de 2019.2, ou seja, $12,5 \%$ dos alunos do curso responderam, aproximadamente. Esse questionário também tem o objetivo de mensurar o quão interessados os discentes estariam em cursar a disciplina Contabilidade Ambiental. De início, foi traçado o perfil de cada discente, destacando-se a idade, gênero e período.

Tabela 1: Perfil dos respondentes - Idade.

\begin{tabular}{|l|l|l|l|l|l|}
\hline Idade & De $\mathbf{1 6}$ a $\mathbf{2 0}$ anos & De 21 a 25 anos & De 26 a $\mathbf{3 0}$ anos & De $\mathbf{3 1}$ a $\mathbf{3 5}$ anos & Acima dos 35 anos \\
\hline Total & $21,7 \%$ & $51,9 \%$ & $16 \%$ & $4,7 \%$ & $5,7 \%$ \\
\hline
\end{tabular}

Tabela 2: Perfil dos respondentes - Gênero.

\begin{tabular}{|l|l|l|l|}
\hline Gênero & Masculino & Feminino & Outro \\
\hline Total & $46,2 \%$ & $53,8 \%$ & $0 \%$ \\
\hline
\end{tabular}

Tabela 3: Perfil dos respondentes - Período.

\begin{tabular}{|c|c|c|c|c|c|c|c|c|}
\hline Período & 19 & 29 & 3ㅇ & 40 & 50 & 69 & 79 & 80 \\
\hline Total & $4,7 \%$ & $3,8 \%$ & $4,7 \%$ & $16 \%$ & $11,3 \%$ & $16,0 \%$ & $7,6 \%$ & $35,9 \%$ \\
\hline
\end{tabular}

Analisando os dados coletados nas tabelas 1, 2 e 3, pode-se notar a predominância de idade de 21 a 25 anos entre os discentes dos cursos, com 51,9\%, representando mais da metade de amostra. No gênero, nota-se uma certa paridade, já que a diferença entre o masculino e feminino foi de apenas 7,6\%, destacandose que nenhum respondente de outro gênero respondeu a pesquisa. No período em que os respondentes estão matriculados, foi pedido para que aqueles que estivessem desblocados fizesse uma equivalência para 
que tivessem respostas apenas até o 8 o período. Foi justamente dos discentes equivalentes ao 8o período que se obtiveram mais respostas, 35,9\%, esperando-se que tenham algum conhecimento sobre a Contabilidade Ambiental.

Além dessas perguntas, foi questionado aos respondentes em que turno estavam matriculados, tendo $47,2 \%$ a noite e $52,8 \%$ a tarde. Também foi perguntando se estagiava/trabalhava, pedindo logo após para especificar se era na área contábil ou não e sendo na área contábil, em que setor. 62,3\% trabalham ou tem um estágio, enquanto $37,7 \%$ não. Desses que trabalham ou estagiam, $64,8 \%$ atuam na área de contabilidade, já 35,2\% não. Vale destacar que o setor com mais respondentes desses que atuam na área da contabilidade, é o contábil, com 43,4\%. Para completar o 10 bloco, foi perguntando se os alunos cursariam as disciplinas de Contabilidade Ambiental ou Gestão Ambiental caso essa fossem ofertadas, se pretendiam se especializar na área caso a resposta para a resposta anterior fosse sim, e se não quisessem se especializar, o porquê.

Tabela 4: Perfil dos respondentes - Interesse.

\begin{tabular}{|l|l|l|}
\hline Cursaria as disciplinas de Contabilidade Ambiental ou Gestão Ambiental caso fossem ofertadas? & Sim & Não \\
\hline Total & $75,5 \%$ & $24,5 \%$ \\
\hline
\end{tabular}

Tabela 5: Perfil dos respondentes - Especialização.

\begin{tabular}{|l|l|l|}
\hline Pretende se especializar na área ambiental? & Sim & Não \\
\hline Total & $20,5 \%$ & $79,5 \%$ \\
\hline
\end{tabular}

Tabela 6. Perfil dos respondentes - Motivos

\begin{tabular}{|l|l|l|l|l|}
\hline $\begin{array}{l}\text { Motivo para não querer } \\
\text { se especializar }\end{array}$ & $\begin{array}{l}\text { Não conhece a área, por isso } \\
\text { não despertou interesse }\end{array}$ & $\begin{array}{l}\text { Falta de } \\
\text { afinidade }\end{array}$ & $\begin{array}{l}\text { Baixa } \\
\text { remuneração }\end{array}$ & $\begin{array}{l}\text { Baixas oportunidades no } \\
\text { mercado de trabalho }\end{array}$ \\
\hline Total & $56,6 \%$ & $25,3 \%$ & $2,4 \%$ & $15,7 \%$ \\
\hline
\end{tabular}

Conforme os dados mostram, 75,5\%, dos discentes que responderam à pesquisa gostariam de cursar as disciplinas Contabilidade Ambiental ou Gestão Ambiental, um número bem elevado. Apesar da maioria querer cursar as disciplinas, dos que cursariam, apenas 20,5\% responderam que fariam uma especialização na área ambiental. Dos outros 79,5\% que responderam que não se especializariam, 56,6\%, mais da metade, afirmaram que o motivo era o não conhecimento da área, não despertando o interesse da especialização. A maioria dos discentes querem cursar a disciplina, porém, o não conhecimento da área faz com que eles não tenham interesse a ponto de se aprofundarem na área.

\section{Importância da área ambiental}

O segundo bloco consiste em mensurar o nível de importância que os respondentes atribuem a área ambiental e até que nível de contato eles tiveram com materiais e experiências dessa área.

Tabela 7: Importância da área ambiental - Materiais e experiências.

\begin{tabular}{|c|c|c|}
\hline QUESTÃO & Sim & Não \\
\hline Já participou de eventos que tratam da Contabilidade Ambiental? & $16 \%$ & $84 \%$ \\
\hline Já teve contato com materiais de Contabilidade Ambiental? (jornais, re & $34 \%$ & $66 \%$ \\
\hline
\end{tabular}

O resultado indica que apenas $16 \%$ dos alunos já participaram de algum evento relacionado a Contabilidade Ambiental, como palestras, por exemplo, e 34\% tiveram algum contato com materiais da área. 
A maioria não teve nenhum contato ou experiências relacionadas a Contabilidade Ambiental. A Tabela 7 mostra a importância dada pelos respondentes em relação a algumas questões da área ambiental. As respostas foram divididas em 5 Níveis: Sem importância, Pouco importante, Importante, Muito importante, Extremamente importante.

Tabela 7: Importância da área ambiental - Grau de importância.

\begin{tabular}{|l|l|l|l|l|l|}
\hline QUESTÃo & $\begin{array}{l}\text { Sem } \\
\text { importância }\end{array}$ & $\begin{array}{l}\text { Pouco } \\
\text { importante }\end{array}$ & Importante & $\begin{array}{l}\text { Muito } \\
\text { importante }\end{array}$ & $\begin{array}{l}\text { Extremamente } \\
\text { importante. }\end{array}$ \\
\hline $\begin{array}{l}\text { Qual a importância de participar de } \\
\text { eventos da área de Contabilidade } \\
\text { Ambiental? }\end{array}$ & $2,8 \%$ & $17,9 \%$ & $39,6 \%$ & $23,6 \%$ & $16 \%$ \\
\hline $\begin{array}{l}\text { Atribua a importância de estar em } \\
\text { contato com materiais de Contabilidade } \\
\text { Ambiental. }\end{array}$ & $1,9 \%$ & $11,3 \%$ & $56,6 \%$ & $17,9 \%$ & $12,3 \%$ \\
\hline $\begin{array}{l}\text { Durante o curso, como os docentes } \\
\text { avaliam em nível de importância a } \\
\text { Contabilidade Ambiental nos dias } \\
\text { atuais? }\end{array}$ & $32,1 \%$ & $54,7 \%$ & $12,3 \%$ & $0,9 \%$ & $0 \%$ \\
\hline $\begin{array}{l}\text { Qual a importância da Contabilidade } \\
\text { Ambiental, na região em que você } \\
\text { mora? }\end{array}$ & $8,5 \%$ & $20,8 \%$ & $24,5 \%$ & $28,3 \%$ & $17,9 \%$ \\
\hline $\begin{array}{l}\text { Qual a contribuição da Ciência Contábil } \\
\text { para o desenvolvimento sustentável? }\end{array}$ & $0,9 \%$ & $7,5 \%$ & $27,4 \%$ & $34,9 \%$ & $29,2 \%$ \\
\hline $\begin{array}{l}\text { O quão importante é adotar uma } \\
\text { Gestão Ambiental bem estruturada } \\
\text { dentro das empresas que desejam } \\
\text { obter vantagens competitivas no } \\
\text { mercado? }\end{array}$ & $0 \%$ & $0,9 \%$ & $26,4 \%$ & $33 \%$ & $39,6 \%$ \\
\hline
\end{tabular}

As respostas mostram que a maioria dos respondentes acham no mínimo importante participar de eventos relacionados a Contabilidade Ambiental, com a maior resposta na alternativa 'Importante', 39,6\% seguido de 'Muito importante', com 23,6\%. Além disso, quase $90 \%$ dos discentes que responderam acham no mínimo importante estar também em contato com matérias da contabilidade ambiental, tendo a maior resposta em 'Importante', 56,6\%.

No quesito que mensura o grau de importância que os docentes do curso de Ciências Contábeis da Universidade Federal de Pernambuco dão para a Contabilidade Ambiental, segundo a perspectiva dos alunos, a maior resposta foi em 'Pouco importante', tendo 54,7\% e logo após, 'Sem importância' tendo 32,1\%, somando $86,8 \%$ as duas. Se tratando da importância da Contabilidade Ambiental na região em que os respondentes moram, $28,3 \%$ consideraram muito importante e $24,5 \%$ importante, sendo as duas maiores opções.

Quanto a contribuição da Ciência Contábil para o desenvolvimento sustentável, as três maiores respostas foram em 'Importante', 'Muito importante' e 'Extremamente importante', com as três juntas somando 91,5\%, mostrando que a grande maioria acredita na contribuição da contabilidade para com o meio ambiente. Seguindo esse caminho, na questão que trata sobre o quão importante é uma empresa ter uma boa gestão ambiental dentro da empresa para ter vantagens competitivas no mercado, a maior resposta foi em 'Extremamente importante' com 39,6\%, seguido de 'Muito importante' com 33\% e importante com $26,4 \%$. 


\section{Conhecimento discente sobre a Contabilidade Ambiental}

No terceiro bloco do questionário foram citados temas que tratam da Contabilidade Ambiental, a fim de mensurar o quanto os respondentes sabem sobre as questões abordadas. Novamente, as respostas foram divididas em 5 Níveis: Nenhum conhecimento, Conhecimento insuficiente, Conhecimento suficiente, Conhecimento quase total, Conhecimento total. As questões foram classificadas de Q1 - Q9 para melhor distinção.

Tabela 8: Grau de conhecimento dos discentes.

\begin{tabular}{|c|c|c|c|c|c|}
\hline TEMAS & $\begin{array}{l}\text { Nenhum } \\
\text { Conhecimento }\end{array}$ & $\begin{array}{l}\text { Conhecimento } \\
\text { insuficiente }\end{array}$ & $\begin{array}{l}\text { Conhecimento } \\
\text { suficiente }\end{array}$ & $\begin{array}{l}\text { Conhecimento } \\
\text { quase total }\end{array}$ & $\begin{array}{l}\text { Conhecimento } \\
\text { total }\end{array}$ \\
\hline $\begin{array}{l}\text { Q1. } \\
\text { Registros de Ativos } \\
\text { Ambientais }\end{array}$ & $40,6 \%$ & $42,5 \%$ & $13,2 \%$ & $2,8 \%$ & $0,9 \%$ \\
\hline $\begin{array}{lrl}\text { Q2. } & \text { Mensuração } & \text { de } \\
\text { Passivos } & \text { Ambientais }\end{array}$ & $49,1 \%$ & $35,9 \%$ & $9,4 \%$ & $4,7 \%$ & $0,9 \%$ \\
\hline $\begin{array}{l}\text { Q.3 Mensuração de } \\
\text { receitas e despesas } \\
\text { ambientais }\end{array}$ & $50,9 \%$ & $37,7 \%$ & $7,6 \%$ & $3,8 \%$ & $0 \%$ \\
\hline $\begin{array}{l}\text { Q4. } \\
\text { Registro na contabilidade } \\
\text { dos Custos ambientais }\end{array}$ & $55,7 \%$ & $32,1 \%$ & $8,4 \%$ & $3,8 \%$ & $0 \%$ \\
\hline $\begin{array}{l}\text { Q5. Estrutura, elaboração } \\
\text { e divulgação do Balanço } \\
\text { Social }\end{array}$ & $50,9 \%$ & $27,4 \%$ & $13,2 \%$ & $7,6 \%$ & $0,9 \%$ \\
\hline $\begin{array}{l}\text { Q.6 Ferramentas de gestão } \\
\text { ambiental como EIAs e } \\
\text { RIMAS }\end{array}$ & $81,2 \%$ & $13,2 \%$ & $4,7 \%$ & $0,9 \%$ & $0 \%$ \\
\hline $\begin{array}{l}\text { Q.7 } \\
\text { Norma ISO } 14000\end{array}$ & $70,9 \%$ & $16 \%$ & $9,4 \%$ & $2,8 \%$ & $0,9 \%$ \\
\hline $\begin{array}{l}\text { Q.8 Marketing verde como } \\
\text { meio de obter vantagens } \\
\text { no mercado }\end{array}$ & $28,4 \%$ & $23,6 \%$ & $32 \%$ & $15,1 \%$ & $0,9 \%$ \\
\hline $\begin{array}{l}\text { Q.9 } \\
\text { Política Nacional de } \\
\text { Resíduos Sólidos - Lei n. } \\
\text { 12.305/2010 }\end{array}$ & $60,4 \%$ & $22,6 \%$ & $10,4 \%$ & $5,7 \%$ & $0,9 \%$ \\
\hline
\end{tabular}

De acordo com a Q1, 40,6\% dos discentes afirmam ter nenhum conhecimento sobre o registro de Ativos Ambientais, e 42,5\% dizem ter conhecimentos insuficientes. Nas questões seguintes, esse alto índice de repostas permanece, tendo 49,1\% afirmando que não tem nenhum conhecimento quanto a Q2 e 35,9\% afirmando que tem conhecimentos insuficientes quanto a mensuração de passivos ambientais. Na Q3, 50,9\% afirmaram não ter nenhum conhecimento na mensuração de receitas e despesas ambientais enquanto 37,7\% disseram ter conhecimento insuficiente. Também vale ressaltar que ninguém responder ter conhecimento total.

$\mathrm{Na}$ Q4, o alto índice de pouco conhecimento permanece, tendo 55,7\% marcando nenhum conhecimento quanto o Registro de Contabilidade da Custos, e 32,1\% afirmando ter conhecimentos insuficiente. Assim como a questão anterior, a Q4 não teve nenhuma resposta que indicasse que algum respondente tem total conhecimento acerca do tema abordado nesse quesito. 50,9\% dizem não saber nada sobre a estrutura e divulgação do Balanço social, enquanto 27,4\% responderam ter conhecimentos insuficientes sobre essa Q5. Na Q6 é onde há a maior porcentagem de desconhecimento acerca do tema 
citado. 81.2\% afirmam não saber nada sobre Ferramentas de Gestão Ambiental e 13,2\% dizem ter conhecimentos insuficientes. Novamente, ninguém responder ter total conhecimento.

Quanto a norma isso, 70,9\% responderam que não tem conhecimento algum, enquanto $16 \%$ responderam ter conhecimentos insuficientes acerca da Q7. A Q8 foi o tema em que houve maior equilíbrio entre as respostas, $28 \%$ afirmaram ter nenhum conhecimento sobre Marketing Verde como meio para se obter vantagens no mercado, enquanto $32 \%$ afirmaram ter conhecimento suficiente. Foi a primeira questão em que um dos maiores foram no mínimo em 'Conhecimento suficiente'. Na Q9, o padrão volta a se repetir, tendo as duas maiores respostas 'Nenhum conhecimento' com 60,4\% e 'Conhecimento insuficiente', com $22,6 \%$.

\section{CONCLUSÕES}

O estudo feito teve como propósito avaliar o nível de conhecimento dos discentes de Ciências Contábeis da Universidade Federal de Pernambuco quando ao tema Contabilidade Ambiental. Para isso, foi aplicado um questionário como instrumento de coleta de dados aos discentes da instituição. Participaram da pesquisa 106 alunos.

A amostra mostrou não só o nível de conhecimento dos discentes, mas também de interesse. Os resultados mostraram que $75,5 \%$ dos alunos estariam interessados em pagar a disciplina caso esta fosse ofertada. Nas perguntas que tratavam o nível de importância da Contabilidade Ambiental e da Área Ambiental em si da perspectiva dos discentes, sempre as respostas com maior percentual foram 'Importante', 'Muito importante' e 'Extremamente importante', mostrando que a maioria dos alunos valorizam a área. Na opinião dos respondentes, os professores não dão muita importância para a Contabilidade Ambiental, tendo 32,1\% opinando que eles não dão importância alguma, e 54,7\% indicando pouca importância. Esses dados mostram um contraste dos discentes e professores. As respostas indicam que os alunos acham importante assuntos que tratam da Contabilidade Ambiental e sentem vontade de cursar uma disciplina que trate desse tema, mas, os professores dos cursos demonstram se importar com determinado tema, o que gera um desconhecimento sobre os assuntos da área.

Esse desconhecimento de temas acerca da Contabilidade Ambiental reflete nas respostas do bloco 3 do questionário, onde em todos os quesitos, exceto na Q8, as respostas mais escolhidas sempre foram 'Nenhum conhecimento' e 'Conhecimento insuficiente'. Deixando a Q8 de lado e a Q5 que juntando essas duas respostas contabiliza $78,3 \%$, todas as outras questões quando juntadas essas duas respostas mais votadas resultam em mais de $80 \%$ dos discentes, mostrando que os respondentes têm um baixo nível de conhecimento acerca da Contabilidade Ambiental e seus temas.

A Contabilidade Ambiental é uma área essencial para o desenvolvimento sustentável e para que as empresas obtenham vantagens no mercado. Com os resultados obtidos, se observa que há uma carência no ensino da Universidade acerca desse tema pouco citado. Desta forma, sugere-se que professores e coordenadores cogitem abordar temas referentes a Contabilidade Ambiental, além da propagação de eventos como acontece com o Terceiro Setor, por exemplo. Uma outra sugestão é que se pense em ofertar 
a disciplina Contabilidade Ambiental ou correlata como eletiva, já que a maioria dos respondentes afirmaram ter interesse em cursá-la, além de atribuir alto grau de importância a temas relacionados.

Para futuras pesquisas se aconselha aumentar a amostra desta pesquisa, dado que ela conseguiu atingir pouco mais de $10 \%$ dos alunos matriculados. Também se aconselha a mensurar o nível de conhecimento dos docentes de Ciências Contábeis da Universidade Federal de Pernambuco sobre o tema Contabilidade Ambiental e áreas correlatas. Além disso, também se recomenda fazer uma pesquisa se a disciplina Contabilidade Ambiental é ofertada em faculdades privadas e públicas do Nordeste, observando como está sendo o aprendizado e fazer comparações quanto ao nível de conhecimento e interesse.

\section{REFERÊNCIAS}

BEUREN, I. M.. Como elaborar trabalhos Monográficos em Contabilidade. São Paulo: Atlas, 2004.

CARVALHO, J. R. M.; ALEXANDRE, F. A. M.; ALMEIDA, K. K. N.; CARVALHO, E. K. M. A.; CURI, W. F.. Uma Análise do Interesse dos Estudantes de Ciências Contábeis pela Área de Contabilidade Ambiental. Revista ambiente contábil, v.2, n.1, p.37-53, 2010.

CHURCHILL JUNIOR, G. A.. Marketing research: methodological foundations. Chicago: The Dryden Press, 1987.

CONCEIÇÃO, F.; FINHANI, G. A.; ALONSO JUNIOR, N.; ALONSO, V. L. C.. Contabilidade Ambiental. XI Simpósio de Excelência em Gestão e Tecnologia, 2014.

FERREIRA, A. C. S.. Contabilidade Ambiental. São Paulo: Atlas, 2003

GALVÃO, T. M.; GARCIA, E. A. R.; ALBUQUERQUE FILHO, A. R.. Nível de compreensão das Notas Explicativas pelos discentes do curso de Ciências Contábeis da Universidade Federal do Ceará. Revista Conbrad, v.4, n.1, p.56-75, 2019

GIL, A. C.. Como elaborar projetos de pesquisa. 6 ed. São Paulo: Atlas, 2014

GONÇALVES, S. S.; HELIODORO, P. A.. A contabilidade ambiental como um novo paradigma. Revista Universo Contábil, v.1, n.3, p.81-93, 2005.

GUIMARÃES, M.. Educação ambiental: no consenso um embate?. Campinas: Papirus, 2000.
LEONARDO, V. S.. Indicadores de desempenho como instrumento de avaliação da gestão ambiental. Revista Contabilidade Vista \& Revista, Belo Horizonte, v.14, n.2, p.29-41, 2003.

MACIEL, C. V.; LAGIOIA, U. C. T.; LIBONATI, J. J.; RODRIGUES, R. N.. Contabilidade ambiental: um estudo exploratório sobre o conhecimento dos profissionais de contabilidade. Revista contemporânea de contabilidade, v.6, n.11, p.137-158, 2009.

MALHOTRA, N. K.. Pesquisa de marketing: uma orientação aplicada. 3 ed. Porto Alegre: Bookman, 2001.

REBOLLO, M. G.. A divulgação de informações ambientais através dos demonstrativos contábeis anuais. Revista ConTexto, Porto Alegre, v.1, n.1, 2001.

RIBEIRO, J. A.. Contabilidade ambiental: estudo sobre o conhecimento dos estudantes e profissionais de contabilidade da cidade de Santana do Ipanema. 2018.

SANTOS, A. O.; SILVA, F. B.; SOUZA, S.. Contabilidade ambiental: um estudo sobre sua aplicabilidade em empresas Brasileiras. Rev. Contab. Finanç., v.12, n.27, 2001.

SEIFFERT, M. E. B.. Gestão ambiental: Instrumentos, Esferas de Ação e Educação Ambiental. 2 ed. São Paulo: Atlas, 2009.

WAINER, J.. Métodos de pesquisa quantitativa e qualitativa para a Ciência da Computação. Atualização em informática, v.1, p.221-262, 2007.

A CBPC - Companhia Brasileira de Produção Científica (CNPJ: 11.221.422/0001-03) detém os direitos materiais desta publicação. Os direitos referem-se à publicação do trabalho em qualquer parte do mundo, incluindo os direitos às renovações, expansões e disseminações da contribuição, bem como outros direitos subsidiários. Todos os trabalhos publicados eletronicamente poderão posteriormente ser publicados em coletâneas impressas sob coordenação da Cognitionis Publishing, da Companhia Brasileira de Produção Científica e seus parceiros autorizados. Os (as) autores (as) preservam os direitos autorais, mas não têm permissão para a publicação da contribuição em outro meio, impresso ou digital, em português ou em tradução. 